\title{
Unsupported Metal Chain Complex: Synthesis, Characterization, and EHMO Study Involving the Tetraosmium Complex $\left[\mathrm{Os}_{2}(\mathrm{CO})_{5}(\text { thd })_{2}\right]_{2}$
}

\author{
Ming-Der Su, ${ }^{\dagger} \mathrm{H}$ sin-Yi Liao, ${ }^{\ddagger}$ San-Yan Chu, ${ }^{\ddagger}$ Yun Chi,, , $\neq$ Chao-Shiuan Liu,, , \\ Feng-J en Lee, ${ }^{\ddagger}$ Shie-Ming Peng, ${ }^{\S}$ and Gene-Hsiang Lee§ \\ School of Chemistry, Kaohsiung Medical University, Kaohsiung 80708, \\ Department of Chemistry, National Tsing Hua University, Hsinchu 30013, and Department of \\ Chemistry and Instrumentation Center, National Taiwan University, \\ Taipei 10764, Taiwan, Republic of China
}

Received J une 23, 2000

\begin{abstract}
Metal carbonyl complex $\mathrm{Os}_{3}(\mathrm{CO})_{12}$ reacts with a hexane solution of (thd) $\mathrm{H}$, thd $=2,2-$ dimethyl-3,5-heptanedionate, in a sealed autoclave at $190{ }^{\circ} \mathrm{C}$ to afford the $\mathrm{Os}_{4}$ metal chain complex $\left[\mathrm{Os}_{2}(\mathrm{CO})_{5}(\mathrm{thd})_{2}\right]_{2}$ (1), isolated from repeated recrystallization in air. Treatment of $\mathbf{1}$ with $\mathrm{CO}$ at room temperature gives the $\mathrm{Os}_{2}$ metal complex $\left[\mathrm{Os}_{2}(\mathrm{CO})_{6}(\text { thd })_{2}\right](\mathbf{2})$ through reversible cleavage of the central Os-Os bond. EHMO calculation has been carried out to explain the involvement of a short-long-short Os-Os...Os-Os array.
\end{abstract}

There has been considerable interest in the generation of the metal chain compounds as their properties may shed light on the reaction patterns and bonding interactions between metal atoms on the molecular scale. ${ }^{1}$ Building such metal complexes normally requires the use of certain bridging carbene and carbyne ligands ${ }^{2}$ or polyamine molecules ${ }^{3}$ that can serve as multidentate bridging ligands to link the metal atoms. However, the corresponding metal chain complexes held together by unsupported metal - metal bonding are rare. Such classes of complexes are best represented by triosmium complexes with the formula $\mathrm{O}_{3}(\mathrm{CO})_{12} \mathrm{X}_{2}, \mathrm{X}=\mathrm{H}, \mathrm{Me}$, and halides, ${ }^{4}$ the anal ogous derivative complexes that contain heterometallic terminus such as $\mathrm{AuPPh}_{3}$ and $\mathrm{SiCl}_{3}, 5$ and the trimetallic complexes involving a donoracceptor metal chain in tandem, ${ }^{6}$ on which the stabilization is provided by the relatively stronger metalmetal bonding involving the third row transition-metal el ements. ${ }^{7}$ To elaborate the possibility for forming the higher nuclearity analogue, we now report the successful synthesis of a compound with a nearly linear chain

${ }^{\dagger}$ Kaohsiung Medical University.

₹ National Tsing Hua University.

$\S$ National Taiwan University.

(1) (a) Cotton, F. A.; Daniels, L. M.; Murillo, C. A.; Pascual, I. J . Am. Chem. Soc. 1997, 119, 10223. (b) Cotton, F. A.; Daniels, L. M.; J ordan, G. T., IV; Murillo, C. A. J . Am. Chem. Soc. 1997, 119, 10377.

(2) (a) Davies, S. J .; Howard, J . A. K.; Mosgrove, R. J .; Stone, F. G. A. Angew. Chem., Int. Ed. Engl. 1989, 28, 264. (b) Hart, I. J .; Hill, A. F.; Stone, F. G. A. J . Chem. Soc., Dalton Trans. 1989, 2261.

(3) (a) Shieh, S. J .; Chou, C. C.; Lee, G. H.; Wang, C. C.; Peng, S. M. Angew. Chem., Int. Ed. Engl. 1997, 36, 56. (b) Lai, S. Y.; Lin, T W.; Chen, Y. H.; Wang, C. C.; Lee, G. H.; Yang, M. H.; Leung, M. K.; Peng, S. M. J . Am. Chem. Soc. 1999, 121, 250.

(4) (a) Moss, J . R.; Graham, W. A. G. I norg. Chem. 1977, 16, 75. (b) Cook, N.; Smart, L.; Woodward, P. J . Chem. Soc., Dalton Trans. 1988, 1744 .

(5) (a) Willis, A. C.; van Buuren, G. N.; Pomeroy, R. K.; Einstein, F. W. B. Inorg. Chem. 1983, 22, 1162. (b) Firfiray, D. B.; I rving, A.; Moss, J. R. J . Chem. Soc., Chem. Commun. 1990, 317. (c) Lewis, J .; M oss, J . R. Can. J . Chem. 1995, 73, 1236.

(6) (a) Batchelor, R. J .; Davis, H. B.; Einstein, F. W. B.; Pomeroy, R. K. J. Am. Chem. Soc. 1990, 112, 2036. (b) Liu, Y.; Leong, W. K.; Pomeroy, R. K. Organometallics 1998, 17, 3387.

(7) Deeming, A. J . Adv. Organomet. Chem. 1986, 26, 1. involving four metal atoms and with the bonding pattern Os-Os...Os-Os, linked together without the bridging ligands.

\section{Experimental Procedure}

General Information and Materials. I nfrared spectra were recorded on a Perkin-Elmer 2000 FT-IR spectrometer. ${ }^{1} \mathrm{H}$ and ${ }^{13} \mathrm{C}$ NMR spectra were recorded on Bruker AMX-300 and AMX-600 instruments; chemical shifts are quoted with respect to internal standard tetramethylsilane $\left({ }^{1} \mathrm{H}\right.$ and ${ }^{13} \mathrm{C}$ NMR). All reactions were performed under a nitrogen atmosphere using deoxygenated solvents dried with an appropriate reagent. Elemental analyses were carried out at the NSC Regional Instrumentation Center at National Cheng Kung University, Tainan, Taiwan.

Reaction of $\mathrm{Os}_{3}(\mathrm{CO})_{12}$ with (thd)H. (thd)H (7 equiv, 0.72 $\mathrm{mL}, 3.88 \mathrm{mmol}), 0.50 \mathrm{~g}$ of $\mathrm{Os}_{3}(\mathrm{CO})_{12}(0.55 \mathrm{mmol})$, and $50 \mathrm{~mL}$ of hexane were added into a $100 \mathrm{~mL}$ stainless steel autoclave. The reactor was sealed under nitrogen and was then slowly heated to $190{ }^{\circ} \mathrm{C}$. After $30 \mathrm{~h}$, the hexane solution was transferred out of the reactor, affording a yellow orange solution which gradually turned dark-purple upon exposure to air. The hexane was evaporated under vacuum, and the residue was dissolved in $\mathrm{CH}_{2} \mathrm{Cl}_{2}$. Then, the insoluble lightyellow powder, which is unreacted $\mathrm{Os}_{3}(\mathrm{CO})_{12}$, was removed by filtration and discarded. The filtrate was concentrated to dryness, and the oily residue was purified by repeated recrystallization using a mixture of $\mathrm{CH}_{2} \mathrm{Cl}_{2}$ and $\mathrm{MeOH}$, affording $140 \mathrm{mg}$ of the dark-red crystalline solid $\left[\mathrm{Os}_{2}(\mathrm{CO})_{5}(\mathrm{thd})_{2}\right]_{2}(\mathbf{1}$, $0.079 \mathrm{mmol}, 20 \%)$.

Spectral data of $\mathbf{1}$. IR $\left(\mathrm{C}_{6} \mathrm{H}_{12}\right): v(\mathrm{CO}), 2076$ (s), 1994 (vs, br), 1925 (m). ${ }^{1} \mathrm{H} \mathrm{NMR}\left(\mathrm{CDCl}_{3}, 294 \mathrm{~K}\right): \delta 6.24(\mathrm{~s}, 2 \mathrm{H}, \mathrm{CH}), 5.67$ $(\mathrm{s}, 2 \mathrm{H}, \mathrm{CH}), 1.18\left(\mathrm{~s}, 36 \mathrm{H}, \mathrm{CH}_{3}\right), 1.10\left(\mathrm{~s}, 36 \mathrm{H}, \mathrm{CH}_{3}\right) .{ }^{13} \mathrm{C} N M R$ $\left(\mathrm{CDCl}_{3}, 294 \mathrm{~K}\right): \delta 199.1$ (4C, CO), 195.5 (4C, CO), 184.1 (4C, $\mathrm{CO}), 178.9$ (2C, CO), 176.8 (4C, CO), 95.7, (2C, CH), 94.2 (2C, $\mathrm{CH}), 41.6\left(4 \mathrm{C}, \mathrm{CMe}_{3}\right), 41.4\left(4 \mathrm{C}, \mathrm{CMe}_{3}\right), 28.4\left(12 \mathrm{C}, \mathrm{CH}_{3}\right), 28.3$ (12C, $\mathrm{CH}_{3}$ ). Anal. Calcd for $\mathrm{C}_{54} \mathrm{H}_{76} \mathrm{O}_{18} \mathrm{Os}_{4}: \mathrm{C}, 36.56 ; \mathrm{H}, 4.32$. Found: $\mathrm{C}, 36.26$; $\mathrm{H}, 4.08$.

Treatment of $\left[\mathrm{Os}_{2}(\mathrm{CO})_{5}(\text { thd })_{2}\right]_{2}$ with $\mathrm{CO}$. A purple solution of $\left[\mathrm{Os}_{2}(\mathrm{CO})_{5}(\text { thd })_{2}\right]_{2}(25 \mathrm{mg})$ in $0.6 \mathrm{~mL}$ of $\mathrm{CDCl}_{3}$ was first placed in a $5 \mathrm{~mm}$ NMR tube. The air in the NMR tube was 
Table 1. Crystallographic Refinement Parameters

\begin{tabular}{|c|c|c|}
\hline & \multicolumn{2}{|c|}{ compounds } \\
\hline & 1 & 2 \\
\hline $\begin{array}{l}\text { formula } \\
\text { mol wt }\end{array}$ & $\begin{array}{l}\mathrm{C}_{54} \mathrm{H}_{76} \mathrm{O}_{18} \mathrm{Os}_{4} \\
1774\end{array}$ & $\begin{array}{l}\mathrm{C}_{28} \mathrm{H}_{38} \mathrm{O}_{10} \mathrm{Os}_{2} \\
914.98\end{array}$ \\
\hline temp, $\mathrm{K}$ & 295 & 150 \\
\hline crystal system & monoclinic & monoclinic \\
\hline space group & $\mathrm{P} 21 / \mathrm{n}$ & $\mathrm{C} 2 / \mathrm{C}$ \\
\hline $\mathrm{a}(\AA)$ & $16.392(1)$ & $15.4880(4)$ \\
\hline $\mathrm{b}(\AA)$ & $10.170(2)$ & $10.2643(3)$ \\
\hline$c(\AA)$ & $19.584(2)$ & $20.8398(5)$ \\
\hline$\beta$ (deg) & $99.476(7)$ & 101.763(1) \\
\hline volume $\left(\AA^{3}\right)$ & $3220.0(7)$ & $3243.4(2)$ \\
\hline Z & 2 & 4 \\
\hline $\mathrm{D}_{\mathrm{c}}\left(\mathrm{g} / \mathrm{cm}^{3}\right)$ & 1.830 & 1.874 \\
\hline$F(000)$ & 1696 & 1752 \\
\hline $\mathrm{h} \mathrm{k} \mathrm{I} \mathrm{ranges}$ & -19 19, 012,023 & $-1920,-1313,-2713$ \\
\hline crystal size, mm & $0.65 \times 0.22 \times 0.16$ & $0.30 \times 0.12 \times 0.04$ \\
\hline$\mu(\mathrm{M} \circ \mathrm{K} \alpha), \mathrm{mm}^{-1}$ & 7.929 & 7.877 \\
\hline $\begin{array}{l}\text { transmission: } \\
\text { max, min }\end{array}$ & $0.365,0.205$ & $0.492,0.305$ \\
\hline no. of data in refnmt & 5645 & 3638 \\
\hline no. of parameters & 344 & 180 \\
\hline $\begin{array}{l}\mathrm{R}_{1}, \mathrm{wR}_{2} \text { with } \\
\mathrm{I}>2 \sigma(\mathrm{I})\end{array}$ & $0.033,0.074$ & $0.036,0.077$ \\
\hline ext. coefficient & $0.00073(4)$ & $0.00021(4)$ \\
\hline $\begin{array}{l}\text { D map, max/min, } \\
\text { e/ } \AA^{-3}\end{array}$ & $1.234 /-1.115$ & $2.278 /-1.932$ \\
\hline
\end{tabular}

removed by purging with $\mathrm{CO}$ gas, during which time a yellow orange solution was immediately obtained. The ${ }^{1 \mathrm{H}}$ and ${ }^{13} \mathrm{C}$ NMR analysis indicated the quantitative conversion to the diosmi um complex $\left[\mathrm{Os}_{2}(\mathrm{CO})_{6}(\text { thd })_{2}\right]$ (2). The solution was then concentrated by passing a relatively fast flow of $\mathrm{CO}$ into the NMR tube. Addition of $\mathrm{MeOH}$ over the top of the concentrated solution resulted in formation of a yellow orange crystalline complex of $\mathbf{2}$ and a small amount of dark blue noncrystalline precipitate over a period of $5 \mathrm{~h}$.

Spectral data of 2. IR $\left(\mathrm{C}_{6} \mathrm{H}_{12}\right): v(\mathrm{CO}), 2049$ (s), 1984 (vs). ${ }^{1} \mathrm{H}$ NMR $\left(\mathrm{CDCl}_{3}, 294 \mathrm{~K}\right): \delta 5.75(\mathrm{~s}, 2 \mathrm{H}, \mathrm{CH}), 1.14\left(\mathrm{~s}, 36 \mathrm{H}, \mathrm{CH}_{3}\right)$. ${ }^{13} \mathrm{C}$ NMR $\left(\mathrm{CDCl}_{3}, 294 \mathrm{~K}\right): \delta 200.1$ (4C, CO), $180.1(4 \mathrm{C}, \mathrm{CO})$, 176.3 (2C, $\mathrm{CO}), 94.0,(2 \mathrm{C}, \mathrm{CH}), 41.4\left(4 \mathrm{C}, \mathrm{CMe}_{3}\right), 28.2$ (12C, $\left.\mathrm{CH}_{3}\right)$.

X-ray Crystallography. Single-crystal X-ray diffraction data were measured on a Bruker SMART CCD diffractometer using $\lambda(\mathrm{M} \circ \mathrm{K} \alpha)$ radiation, $0.7107 \AA$. The data collection was executed using the SMART program. Cell refinement and data reduction were made by the SAINT program. The structure was solved using the SHELXTL/PC program. Anisotropic displacement parameters were used for all non-hydrogen atoms, while the hydrogen atoms were given fixed isotropic displacement parameters. Crystallographic refinement parameters of complexes $\mathbf{1}$ and $\mathbf{2}$ are summarized in Table 1.

Extended Huckel MO Calculation. Extended Hückel calculations were carried out on model complexes $\mathbf{3}, \mathbf{4}$, and $\mathbf{5}$ within the extended Hückel formalism. ${ }^{8}$ Standard atomic distances were taken. The exponents $(\xi)$ and the valence shell ionization potentials $\left(\mathrm{H}_{\mathrm{ii}}\right.$ in eV) were respectively the following: $1.300,-13.60$ for $\mathrm{H}$ 1s; $1.710,-21.40$ for $\mathrm{C} 2 \mathrm{~s} ; 1.625$, -11.40 for $\mathrm{C} 2 \mathrm{p} ; 2.575,-28.20$ for $\mathrm{O} 2 \mathrm{~s} ; 2.275,-12.40$ for $\mathrm{O}$ $2 p ; 1.891,-6.550$ for Os $6 s ; 1.280,-4.000$ for Os $6 p$. The $H_{i i}$ value for Os $5 d$ was at -13.74 . A linear combination of two Slater-type orbitals with exponents $\xi_{1}=3.857$ and $\xi_{2}=1.797$ with the weighting coefficients $\mathrm{c} 1=0.7598$ and $\mathrm{c} 2=0.3899$ was used to represent the Os $5 d$ atomic orbitals.

\section{Results and Discussion}

The required $\mathrm{Os}_{4}$ metal chain complex was prepared from direct treatment of $\mathrm{Os}_{3}(\mathrm{CO})_{12}$ and 2,2,6,6-tetra-

(8) Hoffmann, R. J . Chem. Phys. 1963, 39, 1397.

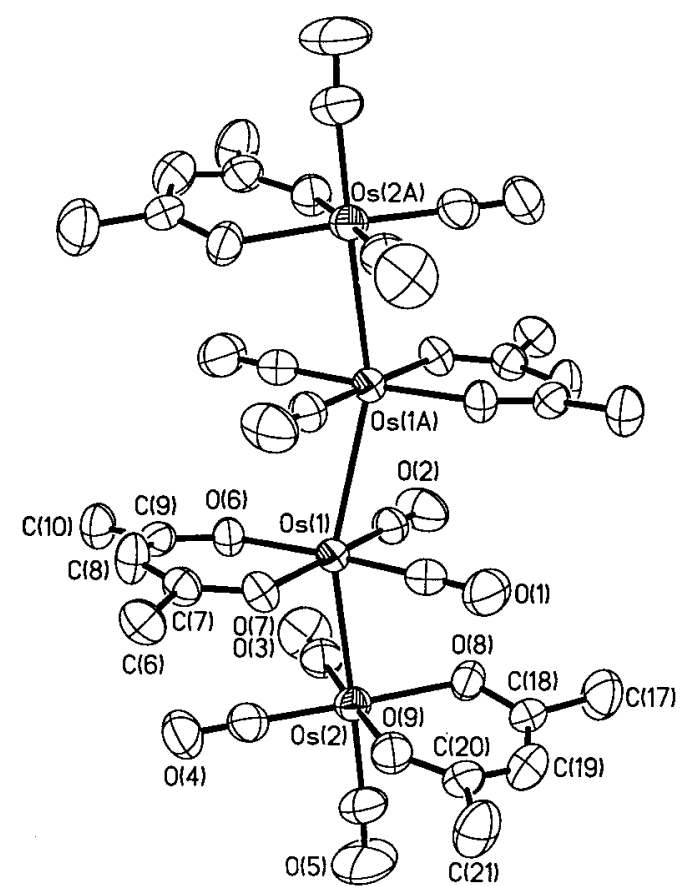

Figure 1. Molecular structure of $\left[\mathrm{Os}_{2}(\mathrm{CO})_{5}(\text { thd })_{2}\right]_{2}(\mathbf{1})$; the methyl groups of the thd ligands were omitted for clarity. Bond distances $(\AA)$ : Os(1)-Os(1) = 2.9778(6), Os(1)$\mathrm{Os}(2)=2.7683(4), \mathrm{Os}(1)-\mathrm{C}(1)=1.831(8), \mathrm{Os}(1)-\mathrm{C}(2)=$ 1.844(8), Os(1)-O(6) = 2.065(5), Os(1)-O(7) = 2.073(5), $\mathrm{Os}(2)-\mathrm{C}(3)=1.892(9), \mathrm{Os}(2)-\mathrm{C}(4)=1.875(9), \mathrm{Os}(2)-\mathrm{C}(5)$ $=1.925(9), \mathrm{Os}(2)-\mathrm{O}(8)=2.069(5)$, and $\mathrm{Os}(1)-\mathrm{O}(9)=$ 2.090(5).

methyl-3,5-heptanedione $(($ thd $) \mathrm{H})$ in a stainless steel autoclave. As described in the Experimental Section, after the reaction was stopped and the hexane solution transferred out of the reactor, the col or of the solution was found to change from orange-yellow to dark-purple during workup, indicating a spontaneous conversion to a secondary product. Thin-layer chromatography was not utilized for product separation as rapid decomposition was noted upon applying the mixture to silica gel. However, a dark brown crystalline product which possesses the formula $\left[\mathrm{Os}_{2}(\mathrm{CO})_{5}(\text { thd })_{2}\right]_{2}(\mathbf{1})$ was isolated by filtration to remove the insol uble material, followed by repeated crystallization using a mixture of $\mathrm{CH}_{2} \mathrm{Cl}_{2}$ and $\mathrm{MeOH}$. Complex 1 shows a very dark color by the naked eye, but the color changed to red-brown under a microscope in bright illumination. Dissolution of $\mathbf{1}$ in $\mathrm{CH}_{2} \mathrm{Cl}_{2}$ afforded a dark-purple sol ution, confirming that it is the secondary product of the original mixture. This complex was then characterized using IR, ${ }^{1} \mathrm{H}$ and ${ }^{13} \mathrm{C}$ NMR, and single-crystal X-ray diffraction.

As indicated in Figure 1, the structure of $\mathbf{1}$ consists of a slightly bent arrangement of Os atoms where the unique Os-Os-Os bond angle is 160.6(1) ${ }^{\circ}$. Each Os unit adopts an octahedral coordination environment involving one thd and at least two CO ligands. The thd ligands are positioned in the anti-anti-anti type of arrangement about the $\mathrm{Os}_{4}$ vector. The ligands of the inner Os atom are arranged in an eclipsed geometry with respect that of the outer Os atoms, while the respective $\mathrm{CO}$ and thd ligands located between the inner Os atoms showed a very different, staggered arrangement. Moreover, the outer Os-Os distance (2.7683(4) $\AA$ ) is shorter than the average Os-Os distance (2.877(3) A) observed in the 


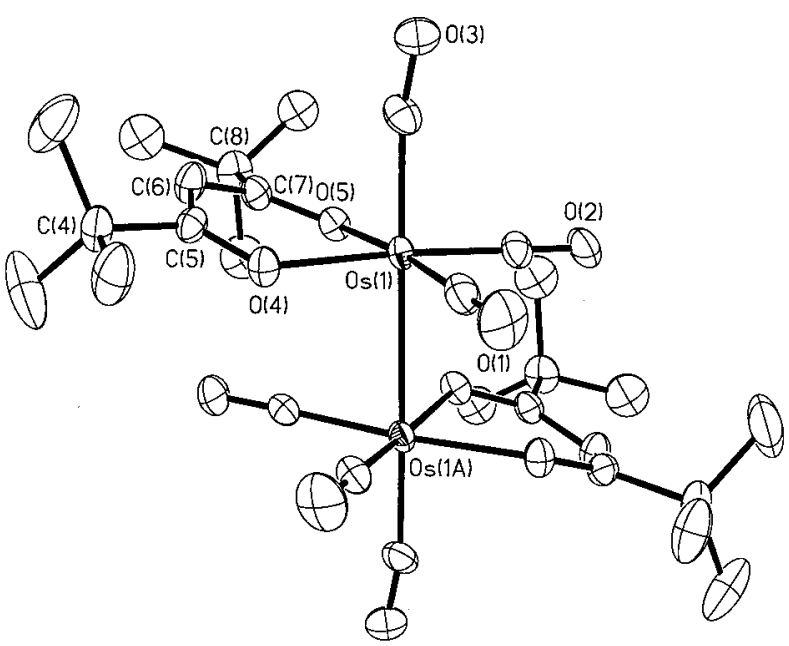

Figure 2. Molecular structure of $\left[\mathrm{Os}_{2}(\mathrm{CO})_{6}(\text { thd })_{2}\right]$ (2). Bond distances $(\AA)$ : Os(1)-Os(1) = 2.8006(5), Os(1)-C(1) = 1.883(6), Os(1)-C(2) = 1.884(6), Os(1)-C(3) = 1.972(7), $\mathrm{Os}(1)-\mathrm{O}(4)=2.102(3)$, and $\mathrm{Os}(1)-\mathrm{O}(5)=2.108(3)$.

parent complex $\mathrm{Os}_{3}(\mathrm{CO})_{12 .}{ }^{9}$ In contrast, the inner OsOs distance (2.9778(6) $\AA$ ) is significantly longer, showing the presence of a weakened metal-metal interaction.

Stirring a $\mathrm{CH}_{2} \mathrm{Cl}_{2}$ solution of $\mathbf{1}$ under $\mathrm{CO}$ at room temperature leads to a rapid col or change from purple to yellow orange; the latter is identical to the color of the original solution obtained from direct treatment of $\mathrm{Os}_{3}(\mathrm{CO})_{12}$ and (thd) $\mathrm{H}$, and suggests formation of the fragmentation product $\left[\mathrm{OS}_{2}(\mathrm{CO})_{6}(\text { thd })_{2}\right](2)$ induced by $\mathrm{CO}$ addition. $\mathrm{A}^{13} \mathrm{C}$ NMR study showed the occurrence of only one set of thd carbonyl signal at $\delta 200.1$ and two additional signals at $\delta 180.1$ and 176.3, assigned to the equatorial and the axial CO ligands, respectively. The formation of a discrete diosmium unit was further confirmed using an $\mathrm{X}$-ray diffraction study on a single crystal, obtained from a mixed solution of $\mathrm{CH}_{2} \mathrm{Cl}_{2}$ and $\mathrm{MeOH}$ under a $\mathrm{CO}$ atmosphere.

The ORTEP diagram of $\mathbf{2}$ is depicted in Figure 2, showing both the staggered arrangement of ligands in the equatorial planes and the occurrence of a similar short Os-Os separation of 2.8006(5) $\AA$. As all these data are consistent with the characteristics of the diosmium $\left[\mathrm{Os}_{2}(\mathrm{CO})_{5}(\mathrm{thd})_{2}\right]$ unit in $\mathbf{1}$, we can confidently concluded that complex $\mathbf{2}$ is the reaction intermediate that gives the generation of metal chain complex $\mathbf{1}$ during the initial reaction between $\mathrm{Os}_{3}(\mathrm{CO})_{12}$ and (thd) $\mathrm{H}$ :

$$
\begin{gathered}
2 \mathrm{Os}_{3}(\mathrm{CO})_{12}+6(\text { thd }) \mathrm{H} \rightarrow \\
3\left[\mathrm{Os}_{2}(\mathrm{CO})_{6}(\text { thd })_{2}\right](\mathbf{2})+3 \mathrm{H}_{2}+6 \mathrm{CO} \\
2(2) \rightleftarrows\left[\mathrm{Os}_{2}(\mathrm{CO})_{5}(\text { thd })_{2}\right]_{2}(\mathbf{1})+2 \mathrm{CO}
\end{gathered}
$$

To gain further insight into the el ectronic structure of the bimetallic and tetrametallic species (i.e., complexes $\mathbf{2}$ and $\mathbf{1}$ ), we have performed extended Hückel (EHMO) calculations for the model complexes $\mathbf{4}$ and $\mathbf{5}$ with geometries analogous to those observed in the solid state.

The analysis is commenced from hypothetical $\mathrm{Os}_{2}$ complex 4, of which the theoretical work on complexes with the structural formula $M_{2} L_{10}$ has already been

(9) Churchill, M. R.; DeBoer, B. G. Inorg. Chem. 1977, 16, 878.

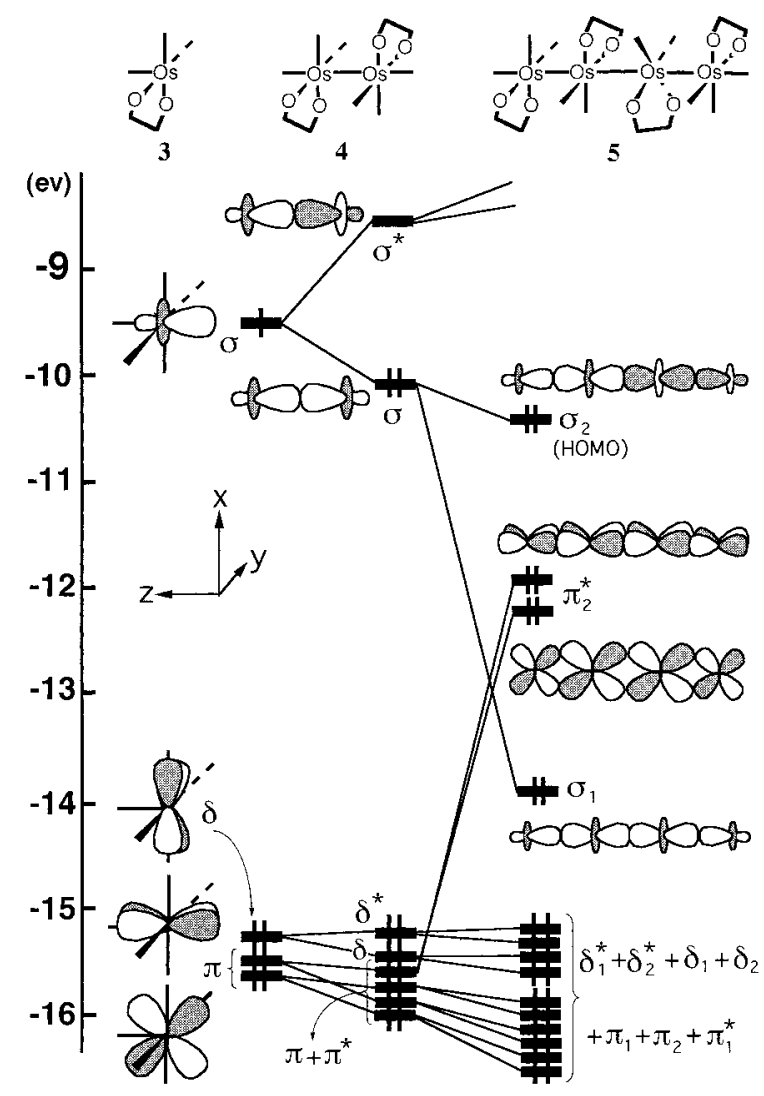

Figure 3. Orbital interaction diagram for the hypothetical dimerization and tetramerization processes.

investigated by a number of approaches. ${ }^{10}$ It is instructive to look first at the frontier orbitals (FMO) of the basic units $\mathbf{3}$ from which complex $\mathbf{4}$ is built up. On the left of the interaction diagram (Figure 3 ), we find three " $t_{2 g}$ " like orbitals, labeled $\delta\left(d_{x y}\right)$ and $\pi\left(d_{x z}, d_{y z}\right)$. Above the " $\mathrm{t}_{2 \mathrm{~g}}$ " orbitals, there are two $\mathrm{d}$ orbitals descendent from the " $\mathrm{e}_{\mathrm{g}}$ " set, i.e., the occupied $\sigma\left(\mathrm{d}_{z^{2}}\right)$ which is higher in energy than the unoccupied $\delta$ with considerable $d_{x^{2}-y^{2}}$ character. As a result, the $\mathrm{Os}_{2}$ complex 4 exhibits a set of eight fragment MOs which span $\sigma^{*}$ and $\sigma$ (out-ofphase and in-phase combinations of the hybrid FMO $\sigma$ ), $\delta^{*}$ and $\delta$ (out-of-phase and in-phase combinations of the $\mathrm{t}_{2 \mathrm{~g}}$-type $\mathrm{FMO} \delta$ ), and $\pi^{*}$ and $\pi$ (out-of-phase and in-phase combinations of the $t_{2 g}$-type $\mathrm{FMO} \pi$ ), for which the ordering of valence MOs is $\pi<\pi^{*}<\delta<\delta^{*}<\sigma<$ $\sigma^{*}$. Since the complex $\mathbf{4}$ belongs to $a d^{7}-d^{7}$ system, this leads to an electron configuration of $(\pi)^{4}\left(\pi^{*}\right)^{4}(\delta)^{2}\left(\delta^{*}\right)^{2}$ $(\sigma)^{2}$ and affords a formal metal - metal bond order of $1 .{ }^{11}$

For complex 5, it should be emphasized that on the basis of our $\mathrm{EH}$ calculations the HOMO $\left(\sigma_{2}\right)$ is well separated from the LUMO (1.77 eV), suggesting that 5 should be stable against spontaneous dissociation. Moreover, the mixing of the dimer FMO $\sigma$, resulting in $\sigma_{2}$ (out-of-phase) and $\sigma_{1}$ (in-phase) orbitals, is of interest.

(10) (a) Cotton, F. A.; Walton, R. A. Multiple Bonds between Metal Atoms; J ohn Wiley: New York, 1982. (b) Heijsen, W.; Baerends, E. J .; Ros. P. Discuss. Faraday Soc. (Symp.) 1980, 14, 211. (c) Shaik, S.; Hoffmann, R.; Fisel, C. R.; Summerville, R. H.J . Am. Chem. Soc. 1980 102, 4555. (d) Nakatsuji, H.; Hada, M.; Kawashima, A. Inorg. Chem. 1992, 31, 1740. (e) Mãrquez, A.; Sanz, J . F.; Gelizé, M.; Dargelos, A. J. Organomet. Chem. 1992, 434, 235.

(11) The el ectron distribution $(\sigma)^{2}(\pi)^{4}(\delta)^{2}\left(\delta^{*}\right)^{2}\left(\pi^{*}\right)^{4}$, characteristic of a $M-M$ single bond, has already been reported, see: Cotton, $F$. A.; DeBoer, B. G.; LaPrade, M. D.; Ripal, J . R.; Ucko, D. A. J . Am. Chem. Soc. 1970, 92, 2926. 
According to our EHMO calculations, there exists a large percentage contribution from the $d_{z^{2}}$ orbitals of the inner Os atoms to the $\sigma_{1}$ and $\sigma_{2}$ orbitals of $\mathbf{5}$ (38\% inner Os and $11 \%$ outer Os, and $51 \%$ inner Os and $16 \%$ outer Os in character for $\sigma_{2}$ and $\sigma_{1}$, respectively). The HOMO $\left(\sigma_{2}\right)$ is ther efore del ocal ized over the entire metal chain, which suggests that all reactions involving gain or loss of electrons will be exclusively metal-centered. It is therefore conceivable that the $\sigma_{1}$ and $\sigma_{2}$ orbitals should play a significant role in determining the final structure. Moreover, since this HOMO is antibonding between the inner Os atoms, but bonding between the outer and inner Os atoms, it suggests that filling this orbital would result in lengthening of the inner Os-Os bond and shortening of the outer Os-Os bonds. In other words, the electronic configuration of 5 is $\cdots \cdots \cdot\left(\delta_{2} *\right)^{2}\left(\sigma_{1}\right)^{2}\left(\pi_{2}{ }^{*}\right)^{4}$ $\left(\sigma_{2}\right)^{2}$ and therefore implies the observation of a strengthened single $\sigma$ bond in the outer Os-Os atoms and a nonbonding interaction in the inner Os-Os atoms, which is qualitatively consistent with the measured OsOs distances observed in $\mathbf{1}$.

Recently, Peng and co-workers have reported a structural study of an isoelectronic rhodium complex, $\left[\mathrm{Rh}_{4^{-}}\right.$ (s-pqdi $\left.)_{2}(\text { pqdi })_{4}(\mathrm{CO})_{4}\right]^{2+}{ }^{12}$ In this distinctive system, the $\mathrm{Rh}$ cations have aligned in a nearly linear chainlike arrangement with distances of 2.848 and $2.858 \AA$ for the outer and inner $\mathrm{Rh}-\mathrm{Rh}$ bonds, respectively. These experimental findings are in good agreement with our predictions. Furthermore, from the chemical bonding point of view, the metal $\sigma$-bonding interaction in $\mathbf{1}$ is equivalent to the well-known $\pi$-bonding of the butadiene molecule which possesses the configuration $\left(\pi_{1}\right)^{2}\left(\pi_{2}\right)^{2} .13$ The $\pi_{1}$ orbital is the in-phase combination of two local ethylene $\pi$ mol ecular orbitals and $\pi_{2}$ is the corresponding out-of-phase combination. In consequence, oxidation of complex $\mathbf{1}$ (or butadiene) should shorten the inner Os-Os distance (or the respective inner $\mathrm{C}-\mathrm{C}$ bond). As there are no relevant experimental data on such system, this prediction remains a pure speculation.

\section{Conclusion}

Treatment of $\mathrm{Os}_{3}(\mathrm{CO})_{12}$ with (thd) $\mathrm{H}$ in a stainless steel autoclave at $190^{\circ} \mathrm{C}$ afforded the diosmium complex $\left[\mathrm{Os}_{2}(\mathrm{CO})_{6}(\mathrm{thd})_{2}\right](\mathbf{2})$, which can be easily converted to the tetrametallic chain cluster $\left[\mathrm{Os}_{2}(\mathrm{CO})_{5}(\text { thd })_{2}\right]_{2}(\mathbf{1})$ by spontaneous elimination of $\mathrm{CO}$ during workup. This dimerization process is somewhat reversible (Scheme $1)$, which is clearly demonstrated by quantitative re-

(12) Chern, S.-S.; Lee, G.-H.; Peng, S.-M. J . Chem. Soc., Chem. Commun. 1994, 1645.

(13) Albright, T. A.; Burdett, J . K.; Whangbo, M.-H. Orbital Interactions in Chemistry; J ohn Wiley: New York, 1985; p 213.
Scheme 1

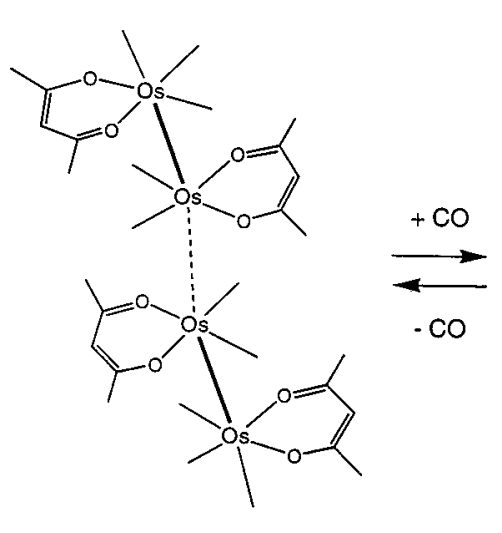

(1)
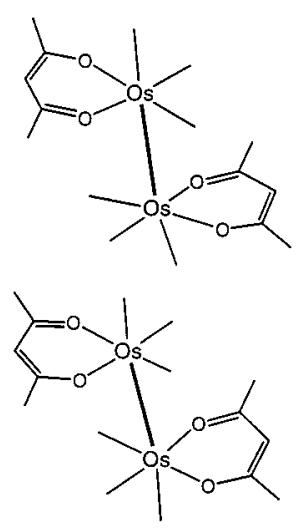

$2 \times(2)$ generation of $\mathbf{2}$ upon addition of $\mathrm{CO}$ in solution at room temperature, as monitored by ${ }^{1} \mathrm{H}$ NMR spectroscopy.

Moreover, complex 1 consists of a nearly linear array of four $\mathrm{d}^{7}$ Os atoms, and the bonding along the metal chain can be illustrated by the simple 18-electron concept. For the $\left[\mathrm{Os}_{2}(\mathrm{CO})_{5}(\text { thd })_{2}\right]$ fragments of $\mathbf{1}$, the terminal Os has $18 \mathrm{e}$ and the inner Os possesses only 16 e due to loss of a 2e donor ligand from 2. Two such fragments can be held together if the inner Os atom of one $\left[\mathrm{Os}_{2}(\mathrm{CO})_{5}(\mathrm{thd})_{2}\right]$ unit donates its $\sigma$ el ectrons to the inner, electron-deficient Os atom of the second $\mathrm{Os}_{2}$ unit. Likewise, the second $\mathrm{Os}_{2}$ unit also uses the same $\sigma$ electron pair donated to the first one, giving a total of 18 electrons for both the inner metal atoms. However, as there are four valence electrons involved in forming sucha double donor-acceptor interaction and affording the electron configuration $(\sigma+\sigma)^{2}(\sigma-\sigma)^{2}=\left(\sigma_{1}^{2} \sigma_{2}^{2}\right)$, formation of the net nonbonding interaction between the inner Os atoms and the strengthened single bond interaction for other Os-Os bonds is expected. Conceptually, this double dative interaction is related to the donor-acceptor interaction observed in several other osmium cluster complexes. ${ }^{6,14}$

Acknowledgment. We thank the National Science Council of the Republic of China for financial support (Grant NSC 88-2113-M-007-034).

Supporting Information Available: X-ray crystallographic file (cif) for $\mathbf{1}$ and $\mathbf{2}$. This material is available free of charge via the Internet at http://pubs.acs.org.

OM000537L

(14) Wang, W.; Einstein, F. W. B.; Pomeroy, R. K. Organometallics 1993, 12, 3079. 